\title{
Electrodeposition of $\mathrm{Bi}_{1-x} \mathrm{Sb}_{\mathrm{x}}$ Films and 200-nm Wire Arrays from a Nonaqueous Solvent
}

\author{
Marisol Martín-González, ${ }^{*}, \dagger$ Amy L. Prieto, ${ }^{\dagger, \S}$ Meredith S. Knox, ${ }^{\dagger}$ \\ Ronald Gronsky, $\neq$ Timothy Sands, ${ }^{\ddagger}, l$ and Angelica M. Stacy ${ }^{\dagger}$ \\ Department of Chemistry and Department of Materials Science and Engineering, \\ University of California-Berkeley, Berkeley, California, 94720
}

Received October 17, 2002. Revised Manuscript Received J anuary 28, 2003

\begin{abstract}
Films and 200-nm wire arrays of $\mathrm{Bi}_{1-x} \mathrm{Sb}_{\mathrm{x}}$ alloys, one of the best known low-temperature thermoelectric materials, have been obtained by electrodeposition without the need for complexing the $\mathrm{Sb}$ cations in solution or further thermal treatment after deposition. The process consists of reduction of $\mathrm{Bi}_{1-x} \mathrm{Sb}_{x}$ directly from a solution of $\mathrm{Bi}\left(\mathrm{NO}_{3}\right)_{3} \cdot 5 \mathrm{H}_{2} \mathrm{O}$ and $\mathrm{SbCl}_{3}$ in dimethyl sulfoxide at $25^{\circ} \mathrm{C}$ on Pt el ectrodes. The el ectrodeposited films are polycrystalline and single phase under slow growth conditions, but two phases are observed under rapid growth conditions (more negative potentials) and for films with roughly equal amounts of $\mathrm{Bi}$ and $\mathrm{Sb}$. 200-nm wire arrays of $\mathrm{Bi}_{1-x} \mathrm{Sb}_{x}$ were grown under similar conditions using porous alumina as a template. Arrays of dense, continuous, and highly crystalline $\mathrm{Bi}_{0.84} \mathrm{Sb}_{0.16}$ wires (close to the predicted optimum composition for thermoelectric applications) have been fabricated successfully at deposition potentials of $-0.28 \mathrm{~V} \mathrm{vs} \mathrm{Ag/AgCl}$ from a solution of $0.050 \mathrm{M} \mathrm{Bi}$ and $0.030 \mathrm{M} \mathrm{Sb}$ in DMSO.
\end{abstract}

\section{Introduction}

There has been ongoing interest in developing thermoelectric devices for widespread use in refrigeration and power generation for the last forty years. Unfortunately, despite intense efforts, the efficiencies of thermoelectric devices have fallen short of those achieved with conventional refrigeration and power generation technologies. In recent years there has been a resurgence of interest in thermoelectric technol ogies because new experimental and theoretical results suggest that the thermoelectric efficiencies of quantum-confined materials are enhanced compared with those of bulk materials. ${ }^{1-4}$ For this reason, our group has been interested in the fabrication of nanowires of thermoel ectric materials.

We have begun studies on the fabrication of $\mathrm{Bi}_{1-x} S b_{x}$ nanowires. $\mathrm{Bi}_{1-x} \mathrm{Sb}_{x}$ alloys are among the best lowtemperature thermoelectric materials in bulk form. The maximum thermoel ectric efficiency (ZT) is found at 80 $\mathrm{K}$ for alloys with $12 \% \mathrm{Sb}(Z \mathrm{~T}=0.88) .^{5-7,10}$ In recent

* To whom correspondence should be addressed via e-mail: msmg@ ole.com. Current address: Instituto de Microelectrónica de Madrid, IMM (CNM-CSIC) C/Isaac Newton, 8 (PTM) 28760, Tres Cantos, Madrid, Spain.

+ Department of Chemistry.

₹ Department of Materials Science and Engineering.

$\S$ Current address: Department of Chemistry and Chemical Biology, Harvard University, 12 Oxford Street, Cambridge, MA 02138.

"Current address: School of Materials Engineering, School of Electrical and Computer Engineering, and the Boirck Nanotechnology Center, Purdue University, 501 N orthwestern Avenue, West Lafayette, IN 47907-2036.

(1) Hicks, L. D.; Harman, T. C.; Dresselhaus, M. S. Appl. Phys. Lett. 1993, 63, 3230-3232

(2) Hicks, L. D.; Dresselhaus, M. S. Phys. Rev. B: Condens. Matter 1993, 47, 16631-16634.

(3) Hicks, L. D.; Dresselhaus, M. S. Phys. Rev. B: Condens. Matter 1993, 47, 12727-12731.

(4) Hicks, L. D.; Harman, T. C.; Sun, X.; Dresselhaus, M. S. Phys. Rev. B: Condens. Matter 1996, 53, 10493-10496. theoretical work, Dressel haus et al. predicted enhancements in $\mathrm{ZT}$ for $\mathrm{Bi}_{1-x} \mathrm{Sb}_{x}$ nanowires with diameters of 35-50 nm. ${ }^{7}$ Our strategy is to fill the high density of pores in porous alumina with $\mathrm{Bi}_{1-x} \mathrm{Sb}_{x}$ nanowires by electrodeposition. ${ }^{8,9}$ By the nature of electrodeposition, the wires will grow continuously. Moreover, with electrodeposition we can control the wire composition by manipulating various deposition conditions such as deposition potential and bath composition.

The first step in the electrodeposition of nanowires is to determine the appropriate conditions for the deposition of high-quality thin films, and then to use those optimized conditions as a starting point for filling the templates. Because $\mathrm{Bi}_{1-x} \mathrm{Sb}_{\mathrm{x}}$ is an alloy, we need to find the optimal conditions that allow for the deposition of $\mathrm{Bi}_{1-x} \mathrm{Sb}_{x}$ with the right composition. Prior work has shown that $\mathrm{Bi}_{1-x} \mathrm{Sb}_{x}$ films can be el ectrodeposited if a means is found to overcome the low solubility of $\mathrm{Sb}$ salts. ${ }^{11-14}$ Besse et al. ${ }^{11}$ have used potentiostatic depositions and complexed the cations in solution with a very

(5) Cho, S. L.; DiVenere, A.; Wong, G. K.; Ketterson, J . B.; Meyer J. R. L. Vac. Sci. Technol., A- 1999, 17, 9-13.

(6) Lenoir, B.; Scherrer, H.; Caillat, T. Recent Trends Thermoelectric Mater. Res. I Semiconductors and Semimetals 2001, 69, 101-137.

(7) Rabin, O.; Lin, Y.-M.; Dresselhaus, M. S. Appl. Phys. Lett. 2001 $79,81$.

(8) Prieto, A. L.; Sander, M. S.; Martín-González, M. S.; Gronsky,

R.; Sands, T.; Stacy A. M. L. Am. Chem. Soc. 2001, 123, 7160.

(9) (a) Sapp, S. A.; Lakshmi, B. B.; Martin, C. R. Adv. Mater. 1999, 11, 402. (b) Martin, C. R. Science 1994, 266, 1961.

(10) Cho, S.; DiVenere, A.; Wong, G. K.; Ketterson, J . B.; Meyer, J . R. Phys. Rev. B: Condens. Matter 1999, 59, 10691-10696.

(11) Besse, F.; Boulanger, C.; Lecuire, J. M. L. Appl. Electrochem. 2000, 30, 385-392.

(12) Shibleva, T. G.; Povetkin, V. V.; Zakharov, M. S. Prot. Met. USSR 1989, 25, 373-374.

(13) Povetkin, V. V.; Shibleva, T. G.; Kovenskii, I. M. Sov. Electrochem. 1990, 26, 1438-1441.

(14) Shibleva, T. G.; Povetkin, V. V.; Zakharov, M. S. J . Appl. Chem. USSR J APUAW 1986, 59, 551.

(15) Martín-González, M. S.; Prieto, A. L.; Gronsky, R.; Sands, T.; Stacy A. M. L. Electrochem. Soc. 2002, 149, C546-C554. 
high concentration of $\mathrm{Cl}^{-}(5 \mathrm{M})$, whereas Shibleva et al. ${ }^{12-14}$ used galvanostatic depositions in the presence of ethylenediaminetetracetic acid (EDTA or Trilon B) as the complexing agent. In both cases, the complexing agents increased the solubility of Sb salts in water. In this paper, we have studied the formation of $\mathrm{Bi}_{1-x} \mathrm{Sb}_{x}$ films and wires by electrodeposition from dimethyl sulfoxide (DMSO) ${ }^{2}$ solutions containing $\mathrm{Sb}^{3+}$ and $\mathrm{Bi}^{3+}$ cations. DMSO was chosen as an alternative to water because of the higher solubility of Sb salts in DMSO than in water. Moreover, in DMSO more negative potentials can be used for film deposition without reduction of the solvent. Several $\mathrm{Sb}$ and $\mathrm{Bi}$ salts are readily soluble in DMSO, so there is a wide choice of starting materials.

Here we report the effects of various electrodeposition conditions (potential, concentration of the cations in solution, electrodes) on the synthesis of $\mathrm{Bi}_{1-x} \mathrm{Sb}_{x}$ films with a range of compositions. In addition, we report the electrodeposition of 200-nm $\mathrm{Bi}_{1-x} \mathrm{Sb}_{x}$ nanowires using porous alumina as a template. The conditions employed for the deposition of thin films were used as a starting point and then optimized to obtain wire arrays with composition close to $15 \% \mathrm{Sb}$ (the composition predicted to yield the maximum ZT form p-type wires by Dresselhaus et al.). The composition and crystallinity of the asdeposited films and nanowire arrays were determined by powder X-ray diffraction, scanning electron microscopy, energy dispersive spectroscopy, and electron microprobe analysis.

\section{Experimental Section}

N ote: For safety reasons gl oves should be worn when using DMSO.

The solutions used for cyclic voltammetry experiments, film deposition, and nanowire depositions were prepared by dissolving $\mathrm{Bi}\left(\mathrm{NO}_{3}\right)_{3} \cdot 5 \mathrm{H}_{2} \mathrm{O}$ (Sigma Chemicals, 99.97\%) and $\mathrm{SbCl}_{3}$ (Sigma, 99.97\%) in DMSO (Fisher, 99.9\%). For cyclic voltammetry experiments solutions of $\mathrm{Bi}^{3+}\left(0.040 \mathrm{M} \mathrm{Bi}\left(\mathrm{NO}_{3}\right)_{3} \cdot 5 \mathrm{H}_{2} \mathrm{O}\right)$, $\mathrm{Sb}^{3+}\left(0.040 \mathrm{M} \mathrm{SbCl}_{3}\right)$, and both together were studied. Films were deposited from three different solutions: (a) $0.020 \mathrm{M} \mathrm{Bi}^{3+}$ and $0.060 \mathrm{M} \mathrm{Sb}^{3+}$; (b) $0.040 \mathrm{M} \mathrm{Bi}^{3+}$ and $0.040 \mathrm{M} \mathrm{Sb}^{3+}$; and (c) $0.060 \mathrm{M} \mathrm{Bi}^{3+}$ and $0.020 \mathrm{M} \mathrm{Sb}^{3+}$. These three solutions will be referred to as having $\mathrm{Bi} / \mathrm{Sb}$ ratios of $3: 1,1: 1$, and $1: 3$, respectively. Nanowires were deposited from two different solutions: (a) $0.060 \mathrm{M} \mathrm{Bi}^{3+}$ and $0.020 \mathrm{M} \mathrm{Sb}^{3+}$ and (b) $0.050 \mathrm{M}$ $\mathrm{Bi}^{3+}$ and $0.030 \mathrm{M} \mathrm{Sb}^{3+}$, referred to with the $\mathrm{Bi} / \mathrm{Sb}$ ratios of 3:1 and 5:3, respectively. In all solutions with mixtures of $B i$ and $\mathrm{Sb}$, the total cation concentration is maintained at $0.080 \mathrm{M}$. A conventional three-electrode cell was used for the el ectrodepositions. All glassware was cleaned in a base bath and thoroughly washed with doubly distilled water.

The mechanism of the electrodeposition of $\mathrm{Bi}_{1-x} \mathrm{Sb}_{x}$ was studied by cyclic voltammetry using a Bioanalytical Systems Basomatic CV50W. This study was carried out under the same conditions as described in ref 15.

The electrodeposition of films was performed potentiostatically as was done in a previous work. ${ }^{15}$ The counter electrode was Pt gauze attached to a Pt wire and the reference el ectrode was $\mathrm{Ag} / \mathrm{AgCl}(3 \mathrm{M} \mathrm{NaCl}, 0.175 \mathrm{~V}$ vs NHE ). Several deposition potentials from $-0.25 \mathrm{~V}$ to $-1.52 \mathrm{~V}$ vs $\mathrm{Ag} / \mathrm{AgCl}(3 \mathrm{M} \mathrm{NaCl})$ and several solution concentrations were examined as well as several working el ectrodes (Ag, Ni, Au/Pd, and Pt). The volume of the bath was $50 \mathrm{~mL}$ and the temperature was $25^{\circ} \mathrm{C}$ for all depositions. Slow stirring was used during deposition of films and 200-nm wires.

The el ectrodeposition of 200-nm wires was performed under similar conditions. The working el ectrode was a 1-cm diam. porous al umina filter with $60 \mu \mathrm{m}$ long and 200-nm diam. pores (obtained from Whatman). A 1- $\mu$ m-thick Pt layer was sputter- deposited on one side (RANDEX, Perkin-E Imer model 2400). The alumina template was then glued to a $\mathrm{Cu}$ disk with $\mathrm{Ag}$ paint and allowed to dry for several hours. The back of the $\mathrm{Cu}$ disk was soldered to a $\mathrm{Cu}$ wire, and painted with an insulating epoxy (Rector Seal) to ensure that deposition could occur only at the base of the pores. This working electrode assembly was then air-dried for at least $12 \mathrm{~h}$. The counter el ectrode and the reference electrode were the same as those used for films. The volume of the bath was $50 \mathrm{~mL}$ and the temperature was $25^{\circ} \mathrm{C}$ for all depositions.

X-ray diffraction (XRD) patterns of the films and wire arrays were obtained using a Siemens D5000 diffractometer. The lattice parameters were calculated by studying the displace ment of the maxima in the diffraction pattern using the substrate (Pt) as an internal standard.

The compositions of the films were determined by electron microprobe analysis (EPMA, Cameca SX-51). The film samples were mounted on glass slides with epoxy and coated with carbon. The microanalyses were performed on 50 different points across the sample. Antimony (99.999\%) and bismuth (99.9999\%) standards were used to calibrate the data. The results presented in this paper are the average over the sites measured, excluding sites within $\sim 2 \mathrm{~mm}$ of the edges of the electrodes. Films grown at less negative potentials were smooth and had standard deviations as low as 0.26 atomic $\%$. However, the standard deviations for films grown at more negative potentials were as high as $8 \%$, presumably due to increased roughness and decreased homogeneity.

Scanning electron microscopy (SEM, Hitachi S-5000) was carried out to determine the morphology of the electrodeposited thin films and the 200-nm wire arrays. Energy-dispersive spectroscopy (EDS, JEOL 6300) was used to estimate the chemical composition of the 200-nm wire arrays. SEM and EDS were performed on the wires by deaving a filled template, and analyzing the sample edge-on. In a typical EDS measure ment, the composition was measured on 10 points along the length of the cross section of the template. The standard deviations of the measurements were within 3 atomic $\%$, which is typical for samples with surface roughness.

\section{Results and Discussion}

In previous electrochemical studies of the deposition of $\mathrm{Bi}_{1-x} \mathrm{Sb}_{x}$ films, $1 \mathrm{M} \mathrm{HCl}$ was used as a solvent. In addition, a high concentration of $\mathrm{NaCl}(4 \mathrm{M})^{11}$ or EDTA $^{12-14}$ was necessary to form the chloro or EDTA complexes of $\mathrm{Sb}^{3+}$ and $\mathrm{Bi}^{3+}$ to promote dissolution. However, even under these conditions, $\mathrm{Sb}^{3+}$ is not very soluble. This limits the ability to tune the solution concentrations, which we will show is key in determining the composition of the electrodeposited films. The advantage of DMSO as a solvent is that a higher concentration of $\mathrm{Sb}$ can be reached by dissolution of $\mathrm{SbCl}_{3}$. In addition, DMSO has a much larger solvent window than water, which allows for the use of a wider range of potentials to tune the film properties without reduction of the solvent.

We have studied the electrochemical behavior of both cations in DMSO. Following the identification of reduction potentials that lead to film formation by cyclic voltammetry, films were deposited from solutions with three different compositions. Finally, 200-nm wire arrays were prepared by deposition into porous alumina templates. These three sets of experiments are described bel ow.

Cyclic Voltammetry. The cyclic voltammogram for both cations together in DMSO is shown in Figure 1. A single very broad reduction wave is observed with $\mathrm{E}_{\mathrm{pc}} \sim-0.65 \mathrm{~V}$, labeled peak $\mathrm{A}$, instead of two different waves corresponding with each cation. This reduction wave can be attributed to the direct deposition of the 


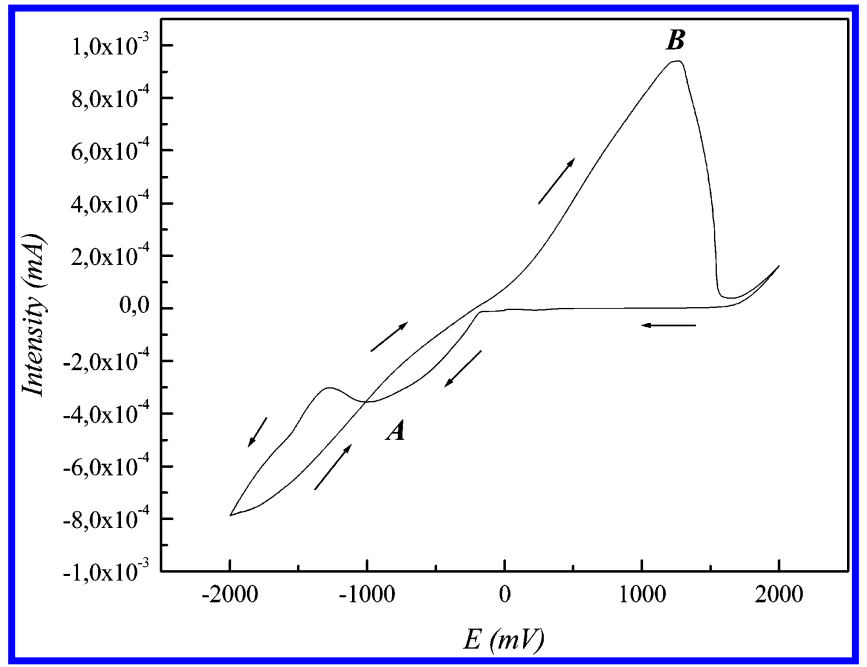

Figure 1. Cyclic voltammetry of $0.040 \mathrm{M} \mathrm{Bi}^{3+}-\mathrm{Bi}\left(\mathrm{NO}_{3}\right)_{3}$. $5 \mathrm{H}_{2} \mathrm{O}$ - plus $0.040 \mathrm{M} \mathrm{Sb}^{3+}-\mathrm{SbCl}_{3}-$. Scan rate, $0.01 \mathrm{~V} / \mathrm{s}^{-1}$; reference electrode, $\mathrm{Ag} / \mathrm{AgCl}(3 \mathrm{M} \mathrm{NaCl})$; temperature, $25^{\circ} \mathrm{C}$.

$\mathrm{Bi}_{1-x} \mathrm{Sb}_{x}$ solid solution according to the following reaction.

$$
(1-x) \mathrm{Bi}^{3+}+(x) \mathrm{Sb}^{3+}+3 \mathrm{e}^{-} \rightarrow \mathrm{Bi}_{1-x} \mathrm{Sb}_{\mathrm{x}}
$$

The observation of a single oxidation peak at $\mathrm{E}_{\mathrm{pa}}=\sim 0.45 \mathrm{~V}$ vs $\mathrm{Ag} / \mathrm{AgCl}$, labeled Peak B, could be due to two different possibilities: (a) the presence of domains of individual elements, one under the other, so that during the oxidation the top layer has to be oxidized first before removing the under layer; or (b) the formation of a solid solution rather than co-deposition of the metals, because a heterogeneous mixture of the two elemental metals would give two oxidation waves corresponding to the independent dissolution of each metal. As will be discussed below, the formation of $\mathrm{Bi}_{1-x} \mathrm{Sb}_{x}$ as opposed to the deposition of $\mathrm{Bi}$ and $\mathrm{Sb}$ layers is confirmed by XRD, as all the diffraction maxima can be indexed with a single phase for films. This confirms that Reaction 1 is the process related to the electrodeposition of $\mathrm{Bi}$ and $\mathrm{Sb}$ in DMSO. This assignment is in good agreement with what has been reported regarding aqueous solutions. ${ }^{16}$

$\mathbf{B i}_{1-\mathbf{x}} \mathbf{S} \mathbf{b}_{\mathbf{x}} \mathbf{F i l m s}$. Before investigation of the composition and morphology of the $\mathrm{Bi}_{1-x} \mathrm{Sb}_{\mathrm{x}}$ films could begin, we needed to find a suitable substrate (working electrode). From the CV and XRD studies, it was evident that $\mathrm{Bi}, \mathrm{Sb}$, and $\mathrm{Bi}_{1-x} \mathrm{Sb}_{x}$ formed stable films on Pt. Although several other electrode materials were subsequently tested $(\mathrm{Ag}, \mathrm{Ni}$, and $\mathrm{Au} / \mathrm{Pd})$, adhesion of the electrodeposited films and film quality were found to be the best on Pt electrodes, as detected by SEM. Because of the higher quality of the films deposited on Pt as opposed to those deposited on the other substrates, Pt electrodes were used for all of the film studies presented in this paper.

Alloys of $\mathrm{Bi}_{1-x} \mathrm{Sb}_{x}$ of varying composition were deposited potentiostatically from solutions of $\mathrm{Bi}\left(\mathrm{NO}_{3}\right)_{3} \cdot 5 \mathrm{H}_{2} \mathrm{O}$ and $\mathrm{SbCl}_{3}$ in DMSO at $25^{\circ} \mathrm{C}$. Two main electrodeposition parameters were studied: (1) potential and (2) relative concentrations of the cations in solution.

(16) Sutkus, A.; Tolutis, R. Phys. Status Solidi A 1999, 173, 417-

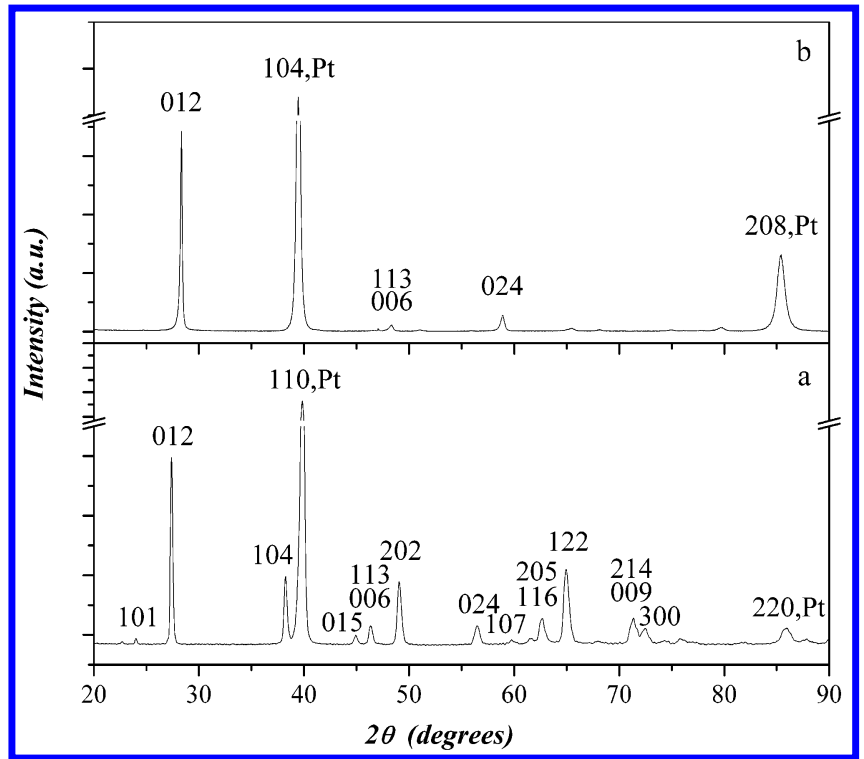

Figure 2. XRD patterns of two $\mathrm{Bi}_{1-x} \mathrm{Sb}_{\mathrm{x}}$ films. The films were obtained from two solutions: (a) $0.02 \mathrm{M} \mathrm{Bi}^{3+}$ plus $0.06 \mathrm{M} \mathrm{Sb}^{3+}$; and (b) $0.06 \mathrm{M} \mathrm{Bi}^{3+}$ plus $0.02 \mathrm{M} \mathrm{Sb}^{3+}$. The depositions were carried out at $\mathrm{E}=-1.02 \mathrm{~V}$ vs $\mathrm{Ag} / \mathrm{AgCl}(3 \mathrm{M} \mathrm{NaCl})$ for $1 \mathrm{~h}$. The film compositions are $\mathrm{Bi}_{0.95} \mathrm{Sb}_{0.05}$ and $\mathrm{Bi}_{0.10} \mathrm{Sb}_{0.90}$, respectively, as determined by EPMA.

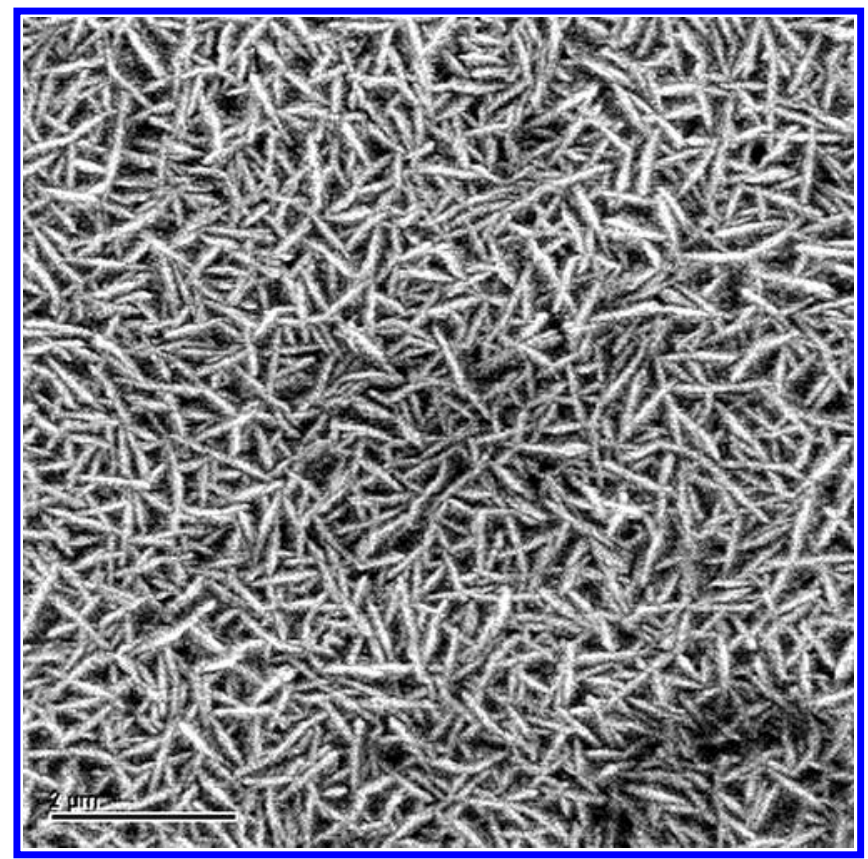

Figure 3. SEM micrograph of a film with composition $\mathrm{Bi}_{0.10} \mathrm{Sb}_{0.90}$. The features are characteristic of all the films deposited at $-1.02 \mathrm{~V}$ vs $\mathrm{Ag} / \mathrm{AgCl}(3 \mathrm{M} \mathrm{NaCl})$ for $1 \mathrm{~h}$.

For $\mathrm{Bi} / \mathrm{Sb}$ ratios of $1: 3$ in solution, films were deposited at potentials of $-1.02 \mathrm{~V}$ and $-1.52 \mathrm{~V}$ vs $\mathrm{Ag} / \mathrm{AgCl}$. For both deposition potentials, the films were approximately $10 \% \mathrm{Bi}$ and $90 \% \mathrm{Sb}$ as determined by EPMA. These values were consistent at more than 50 locations across the film (excluding regions within $2 \mathrm{~mm}$ of the edges), indicating that the films are relatively homogeneous. The peaks in the XRD patterns were sharp and narrow, indicating that the films are highly crystalline and consist of only one phase (Figure 2a). The peaks are slightly shifted to larger $d$ spacing as compared with those of pure Sb, which is consistent with the formation of a solid solution. As can be seen in the 
Table 1. Atomic Percentages of Bi/Sb in Films Electrodeposited on Pt Electrodes as a Function of Bi and Sb Concentration ${ }^{a}$

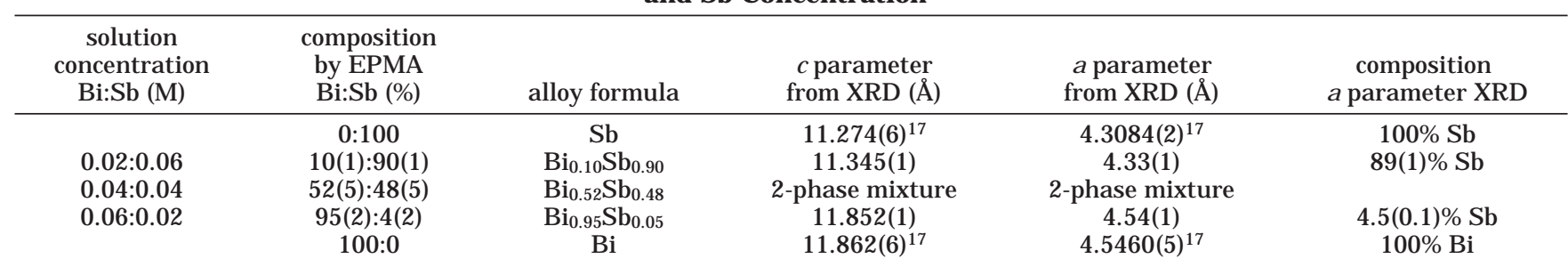

a Solutions were prepared by dissolving $\mathrm{Bi}\left(\mathrm{NO}_{3}\right)_{3} \cdot 5 \mathrm{H}_{2} \mathrm{O}$ and $\mathrm{SbCl}_{3}$ in $\mathrm{DMSO}$, and the depositions were carried out at $-1.02 \mathrm{~V}$ vs $\mathrm{Ag} /$ $\mathrm{AgCl}(3 \mathrm{M} \mathrm{NaCl})$ for $1 \mathrm{~h}$ at $25^{\circ} \mathrm{C}$. The percentages of $\mathrm{Bi}$ and $\mathrm{Sb}$ were determined by EPMA and from the a lattice parameter using Berger's formula. ${ }^{17}$

SEM image shown in Figure 3, films grown at $-1.02 \mathrm{~V}$ are smooth with a relatively small grain size $(\sim 600 \times$ $80 \mathrm{~nm})$.

For $\mathrm{Bi} / \mathrm{Sb}$ ratios of $1: 1$ in solution and deposition potentials of $-1.02 \mathrm{~V}$ and $-1.52 \mathrm{~V}$ vs $\mathrm{Ag} / \mathrm{AgCl}$, the films produced were roughly $50 \% \mathrm{Bi}$ and $50 \% \mathrm{Sb}$ as determined by EPMA. As the electron probe was scanned across the film, these numbers fluctuated by $\pm 15 \%$ indicating that the films are not as homogeneous as the Sb-rich films. Although the deposition potential had little effect on the overall film composition, the XRD patterns for each sample were markedly different. At the more negative potential, $-1.52 \mathrm{~V}$, there were two sets of peaks near those of both pure $\mathrm{Sb}$ and pure $\mathrm{Bi}$, indicating the co-deposition of two phases (one Bi-rich and the other one Sb-rich). In contrast, the XRD patterns for the films deposited at $-1.02 \mathrm{~V}$ show only a single alloy phase with peaks between those of pure $\mathrm{Sb}$ and pure $\mathrm{Bi}$ (albeit broader than those for the Sb-rich films). The films prepared at the more negative potential were also quite rough as determined by SE M, indicative of rapid growth. We conclude that single alloy films with roughly equal amounts of both $\mathrm{Sb}$ and $\mathrm{Bi}$ can be obtained for potentials that are not overly negative. At very negative potentials, rapid growth leads to codeposition of two phases with different compositions as opposed to one solid solution.

$\mathrm{F}$ or $\mathrm{Bi} / \mathrm{Sb}$ ratios of $3: 1$ in solution, a composition in the range of interest for thermoelectric applications was expected. Therefore, a wider range of potentials was tested from -0.27 to $-1.52 \mathrm{~V}$ vs $\mathrm{Ag} / \mathrm{AgCl}$ to determine in more detail the range of compositions accessible. The films produced were all $\mathrm{Bi}$-rich, with roughly $95 \% \mathrm{Bi}$ and $5 \% \mathrm{Sb}$. The peaks in the XRD patterns were all relatively narrow, indicating a high degree of crystallinity, and only one compositional phase was observed (Figure 2b). The peaks are slightly shifted to smaller d spacing as compared with those of pure $\mathrm{Bi}$, which is consistent with the formation of a solid solution. The dominant crystalline orientation depends on the chemical composition. SEM images of the Bi-rich films are in Figure 3 with an average crystallite size of $1 \times 0.1 \mu \mathrm{m}$.

XRD patterns were further analyzed to obtain information about the correlation of lattice parameters with composition. As expected for a solid solution, there is a shift toward larger angles in $2 \theta$ with an increase in $\mathrm{Sb}$ concentration. The lattice parameters obtained using Pt as an internal standard are given in Table 1 . There is a systematic decrease in both a and c parameters with increasing $\mathrm{Sb}$ content, consistent with the expected decrease in cell volume. Berger et al. ${ }^{17}$ determined a correlation between cell parameters and the value of $x$ in $\mathrm{Bi}_{1-x} \mathrm{Sb}_{x}$ alloys:

$$
\begin{gathered}
a=(0.454469 \pm 0.00044)-(0.02398 \pm 0.00072) x \\
c=1.186294-[0.058632 /(1+((1.260 \pm \\
0.043) *(1 / x-1)))]
\end{gathered}
$$

Those compositions calculated using Berger's correlation and the values of a as determined from XRD are in good agreement with the relative concentrations as determined by EPMA (see Table 1).

We conclude that the films prepared by electrodeposition are a solid solution, and not a physical mixture of $\mathrm{Bi}$ and $\mathrm{Sb}$, with the exception of films of roughly equal amounts of $\mathrm{Bi}$ and $\mathrm{Sb}$ and films that are grown too rapidly (at more negative potentials). The compositions of the films are strongly correlated with the relative concentrations of the $\mathrm{Bi}$ and $\mathrm{Sb}$ in solution, and less dependent on other factors such as the potential and the deposition time. Compositions obtained under slow growth conditions for different el ectrol yte compositions are compared in Table 1. The composition of the films becomes more $\mathrm{Bi}$-rich as the ratio of $\mathrm{Bi} / \mathrm{Sb}$ is increased. Both Sb-rich and Bi-rich films prepared at the same potential show similar morphology. A representative example can be found in Figure 3. The dependence of the ratio of $\mathrm{Bi} / \mathrm{Sb}$ in solution to the composition of $\mathrm{Bi}$ and $\mathrm{Sb}$ in the deposited solid solution is in good agreement with what has been observed for alloys deposited from aqueous solutions. ${ }^{11-14}$

200-nm $\mathbf{B i}_{1-x} \mathbf{S b}_{\mathbf{x}}$ Wires. Arrays of $\mathrm{Bi}_{1-x} \mathrm{Sb}_{x}$ nanowires with $200 \mathrm{~nm}$ diameters were fabricated by electrodeposition into porous alumina to determine whether high-quality nanowires could be made. We started with the conditions used for the films, and then tuned the parameters to get better wires. DMSO solutions with $\mathrm{Bi} / \mathrm{Sb}$ ratios of 3:1 and 5:3 were used. Because slow growth conditions lead to more highly crystalline nanowires and a higher degree of pore filling, less negative potentials were used for nanowire growth: $-0.52 \mathrm{~V}$ and $-0.28 \mathrm{~V}$ vs $\mathrm{Ag} / \mathrm{AgCl}$.

Depositions performed at $-0.52 \mathrm{~V}$ vs $\mathrm{Ag} / \mathrm{AgCl}$ with a $\mathrm{Bi} / \mathrm{Sb}$ ratio of 3:1 produced wires that were $7 \% \mathrm{Sb}$ and $93 \% \mathrm{Bi}$ as determined by EDS along the cross-section of the template. The XRD pattern of this sample indicates that polycrystalline wires are obtained, with a slight co-deposition of $\mathrm{Sb}$, as indicated by the presence of a small $\mathrm{Sb}_{012}$ peak (F igure 4). This peak does not have any displacement with respect to the PDF file. This Sb

(17) Berger, H.; Christ, B.; Troschke, J . Cryst. Res. Technol. 1982, 17, 1233. 


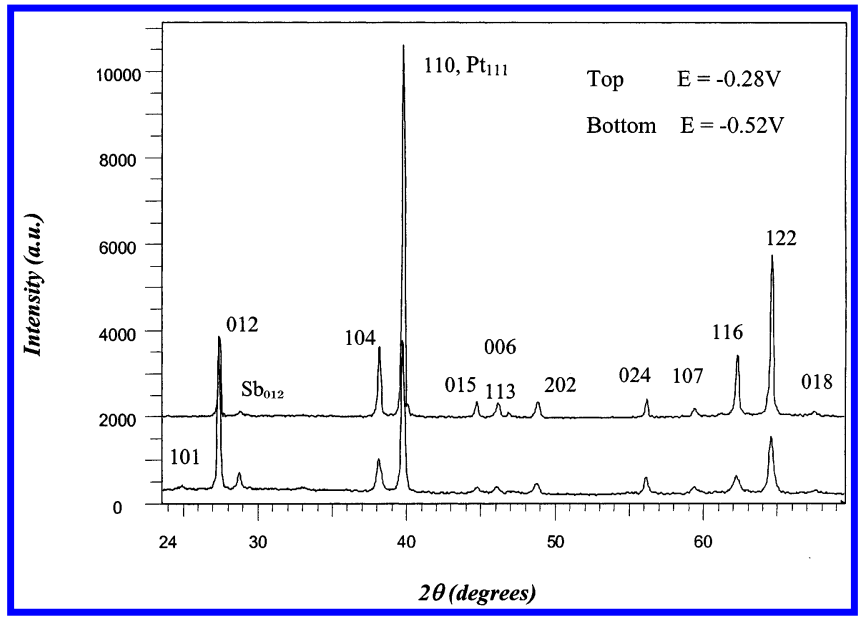

Figure 4. XRD patterns of $200-\mathrm{nm} \mathrm{Bi/Sb}$ wire arrays deposited at $\mathrm{E}=-0.52 \mathrm{~V}$ and $-0.28 \mathrm{~V}$ vs $\mathrm{Ag} / \mathrm{AgCl}$ from a bath of $0.06 \mathrm{M} \mathrm{Bi}$ and $0.02 \mathrm{M} \mathrm{Sb}$. The Miller indices indicate the alloy peaks. The peak widths are narrower for the slower growth conditions $(\mathrm{E}=-0.28 \mathrm{~V})$, indicating a more homogeneous sample.

peak was not found for films. By using slower growth conditions ( $\mathrm{E}=-0.28 \mathrm{~V})$, a sample that exhibits narrower peak widths in the XRD is obtained, indicating a more homogeneous sample. The composition of the wires remained the same within the error of the measurement. The $\mathrm{Sb}_{012}$ peak seems, a priori, to be lower in intensity relative to the alloy peaks, for $-0.28 \mathrm{~V}$, which can be due to a lesser amount of $\mathrm{Sb}$ in the deposit or more probably to a change in the relative intensity of the diffraction peak due to an increase in the homogeneity and the orientation of the wires. This is also in agreement with the narrower peaks observed for the alloy films. We conclude that the Bi-rich phase that forms at $-0.28 \mathrm{~V}$ is reasonably homogeneous, indicating that the wires are more homogeneous for slower growth rates.

The presence of essentially pure $\mathrm{Sb}$ is intriguing. If the second phase were due to phase separation, we would expect an Sb-rich phase, not pure $\mathrm{Sb}$. When the $\mathrm{Pt}$ and the bottom 1-2 $\mu \mathrm{m}$ of template were removed by mechanical polishing the XRD pattern showed no evidence of the $\mathrm{Sb}_{012}$ peak. Therefore, we can conclude that the pure Sb seems to be deposited in the first stages of the el ectrodeposition process for deposition into porous alumina, followed by the deposition of $\mathrm{Bi}_{1-x} \mathrm{Sb}_{x}$ alloy.

The observation of the initial deposition of $\mathrm{Sb}$ followed by the deposition of Bi-rich alloys suggests two main deposition stages. In the early stages, the electrodeposition is governed by formation of the double layer, adsorption phenomena, equilibrium between cations, surface characteristics of the electrode, and/or molecular-scal e events, etc. These processes affect the relative concentration of $\mathrm{Bi}$ and $\mathrm{Sb}$ within the pores near the electrode differently compared with the relative concentrations in the bulk solution. On the basis of our results, we conclude that the conditions in the early stages seem to favor either the deposition of pure Sb or the co-deposition of $\mathrm{Bi}_{1-x} \mathrm{Sb}_{x}$ and $\mathrm{Sb}$. Once steady state conditions are reached, the main process that governs the relative concentration of the cations is the mass transport from the bulk toward the surface of the

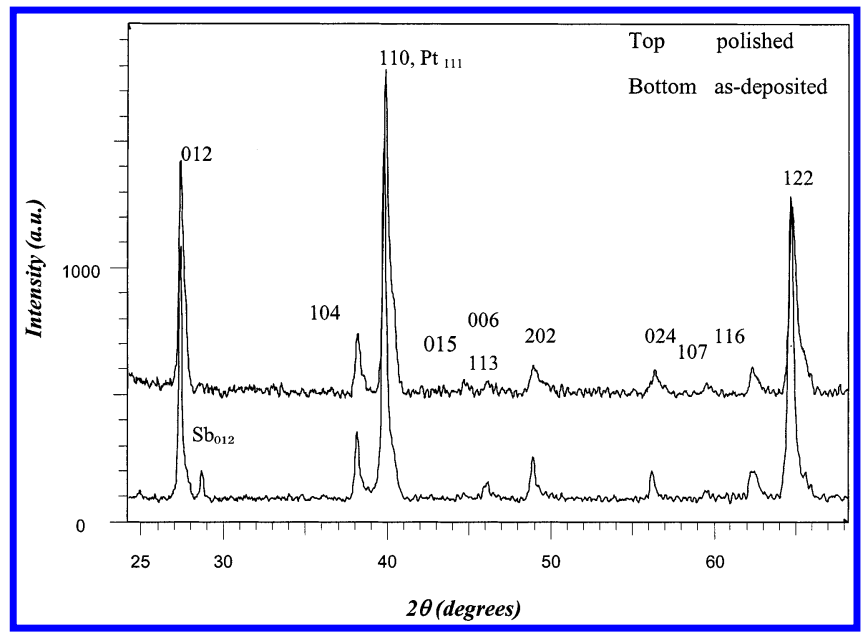

Figure 5. XRD pattern of 200-nm Bi/Sb wire array grown at $\mathrm{E}=-0.28 \mathrm{~V}$ vs $\mathrm{Ag} / \mathrm{AgCl}$ from a bath of $0.05 \mathrm{M} \mathrm{Bi}$ and $0.03 \mathrm{M}$ $\mathrm{Sb}$. EDS shows that the average composition of the wires is $\mathrm{Bi}_{0.86} \mathrm{Sb}_{0.14}$. Once the Pt substrate and $\sim 1 \mu \mathrm{m}$ of the bottom of the wires has been removed, the peaks associated with $\mathrm{Sb}$ disappear. Note that the shoulders on the peaks indicate a small degree of inhomogeneity. Also, the high intensity of the 110 peak relative to the 012 peak indicates that the wire texture is [110].

nanoelectrodes. During this stage, we observed the deposition of Bi-rich alloy wires, which are reasonably homogeneous.

To obtain wires with a higher Sb composition, depositions were performed at $-0.28 \mathrm{~V}$ vs $\mathrm{Ag} / \mathrm{AgCl}$, but with a $\mathrm{Bi} / \mathrm{Sb}$ ratio of 5:3 (relatively richer in $\mathrm{Sb}$ ). With this bath composition, the wire composition was richer in $\mathrm{Sb}, 14 \% \mathrm{Sb}$ and $86 \% \mathrm{Bi}$, as determined by EDS. This composition is in the range of interest for predicted enhancements in thermoelectric efficiency. The peaks in the XRD pattern are narrow (although shoulders can be observed in some of the peaks indicating a range of compositions) and shifted toward higher $2 \theta$ as expected (Figure 5). The high intensity of the 110 peak relative to the 012 peak indicates that the wire texture is [110]. The $\mathrm{Sb}_{012}$ peak is still observed, which indicates that there is still a preferential deposition of $\mathrm{Sb}$ at the bottom of the pores due to processes related to the initial stages of the electrodeposition.

SEM images of the bottom of the template after removal of the electrode material (Pt) by mechanical polishing (Figure 6a) show that nucleation occurs in greater than $95 \%$ of the pores. This is important because a high wire density is required for thermoelectric applications. I mages of the cross-section, Figure $6 b$, of the templates show that the wires are dense and continuous. Small gaps can be found between the template and some of the wires, marked with an arrow. Nonwetting effects between the alumina and the $\mathrm{Bi}_{1-x} S b_{x}$ solid solution could explain this behavior. Similar behavior has been observed for both 200-nm and 40-nm $\mathrm{Bi}_{2-x} \mathrm{Sb}_{x} \mathrm{Te}_{3}^{18}$ and $40-\mathrm{nm} \mathrm{Bi}_{1-x} \mathrm{Sb}_{x_{1}}{ }^{19}$ but not $\mathrm{Bi}_{2-}$ $\mathrm{Te}_{3}{ }^{8}$ or $\mathrm{Bi}^{20}$ in porous alumina. Moreover, different

(18) Martín-González, M. S.; Prieto, A. L.; Gronsky, R.; Sands, T.; Stacy, A. M. Adv. Mater. 2003, in press.

(19) Prieto, A. L.; Martín-González, M. S.; Gronsky, R.; Sands, T.; Stacy, A. M. L. Am. Chem. Soc. 2003, 125, 2388-2389.

(20) Yin, A.J .; Li, J .; Jian, W.; Bennett, A.J .; Xu, J . M. Appl. Phys. Lett. 2001, 79, 1039. 


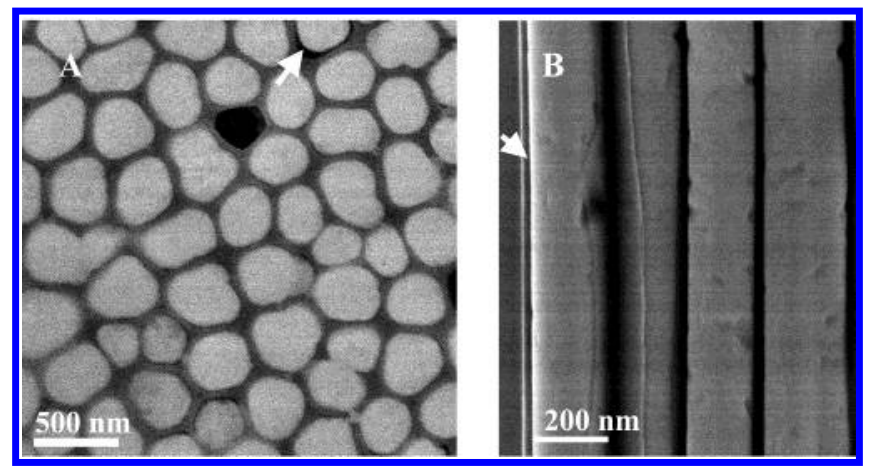

Figure 6. $\mathrm{SEM}$ nanowires of $\mathrm{Bi}_{0.85} \mathrm{Sb}_{0.15}$ nanowires: (a) bottom view after removal of the Pt electrode by mechanical polishing; and (b) cross-section or edge view. The lighter regions are the wires. They are dense. The filling of each pore is very high, yet does not completely fill the pores in all regions (gap marked with an arrow). Nucleation and growth of wires occurs in greater than $95 \%$ of the pores.

solvents(water and DMSO) have also been used for $\mathrm{Bi}_{2-x} \mathrm{Sb}_{x} \mathrm{Te}_{3}$ and $\mathrm{Bi}_{1-x} \mathrm{Sb}_{x}$, respectively.

\section{Conclusions}

Films and 200-nm wire arrays of $\mathrm{Bi}_{1-x} \mathrm{Sb}_{x}$ solid solutions can been electrodeposited directly by a threeelectron reduction from solutions of $\mathrm{Bi}^{3+}$ and $\mathrm{Sb}^{3+}$ in DMSO without further thermal treatment or the need for complexing the $\mathrm{Sb}^{3+}$ in solution. Under slow growth conditions and a relative concentration of $\mathrm{Bi} / \mathrm{Sb}$ of $1: 3$ and $3: 1$, the films deposited are smooth, single-phase (Sb-rich and Bi-rich, respectively), and crystalline. Codeposition can be observed for films grown from solutions with roughly equal amounts of $\mathrm{Sb}$ and $\mathrm{Bi}$ under rapid growth conditions. Arrays with $200-\mathrm{nm} \mathrm{Bi}_{0.84} \mathrm{Sb}_{0.16}$ wires can be obtained at room temperature from a solution with a $\mathrm{Bi} / \mathrm{Sb}$ ratio of $5: 3$ in DMSO and a potential of $-0.28 \mathrm{~V}$ vs $\mathrm{Ag} / \mathrm{AgCl}$. The wires are dense and continuous, and they almost completely fill the pores.

Acknowledgment. This work was funded by the Office of Naval Research (ONR N00014-01-1-1058). Additional support was provided by the Department of Defense ONR-MURI on Thermoelectrics, N 00014-97-10516. We thank Margaret Chan and Andrea Kops for their help in the fabrication of the films, J enny Keyani for her help in the fabrication of the 200-nm nanowires, Professor J effrey Long and his group for the use of the Bioanalytical Systems Basomatic CV50W, Dr. Gordon Vrdoljak for help with the SEM (Electron Microscope Lab, UCB), J ohn Donovan for help with the EPMA (Electron Probe Microanalysis Laboratory, UCB), and Ron Wilson for help with the SEM/EDS system (Department of Materials Science and Engineering). M.S.M.G thanks the MEC/Fulbright Postdoctoral Fellowship program and A.L.P. thanks Lucent Technologies, Bell Labs for funding.

\section{CM021027F}

